\title{
Taşbaskı Halk Resimleri ve Kahvehane Kültürü
}

\author{
Arş. Gör. Yeliz Selvi
}

\section{Özet}

Taşbaskı halk resimleri, Anadolu halkının kültürü ve gelenekleri doğrultusunda, inanç ve duygularını dile getirmek için halk sanatçıları tarafından yapılmışıı. Bu resimler ile kahvehane ve bu mekânın kendine has kültürü arasında önemli bir ilişki vardır. Kahvehane ilk kez 16. yüzyılda Mekke'de açılmışıı. 16. yüzyılın ikinci yarııında ise ticari kaygılarla Halep'ten ve Şam'dan gelen iki kişi resmî olarak istanbul'da ilk kahvehaneyi açmışlardır. Kahvehanelerde zaman içerisinde heterojen bir kültür oluşmuştur. Bu kültürün kendine has özellikleri ise taşbaskı halk resimlerine biçimsel ve tematik olarak yansıtılmışır. Çoğu zaman iç mekân dekorasyonunda kullanılan ve konu bakımından son derece zengin olan bu resimler, yörelere, halkın inanç ve eğitim seviyesine, bireyin sosyal statüsüne ve bu dinamiklere göre şekillenen kahvehanelerin türüne göre çeşitlemeler göstermektedir.

\section{LITHOGRAPY FOLK PAINTINGS AND COFFEEHOUSE CULTURE}

\section{Abstract}

Lithography folk paintings are made by folk artists in order to express the beliefs and feelings in accordance with the culture and traditions of the people of Anatolia.There is a close relationship between these paintings and the coffeehouse andthe unique culture of this place. The first coffeehouse were opened in Mecca in the 16th century. Two people from Aleppo and Damascus officially opened the first coffeehouse in Istanbul in the second half of the 16th century. A heterogeneous culture has been formed over time in coffeehouses. The specific characteristics of this culture is reflected as formal and thematic to the lithography folk paintings. These pictures that is often used for interior decoration and be extremely rich in terms of subject matter shows variations according to regions, people of faith and level of education, and the social status of person and the type of coffeehouses that is shaped by these dynamics.

\section{Anahtar} Kelimeler Taşbaskı

Kahvehane

Kültür

\section{Keywords}

Lithography

Coffeehouse

Culture 
Kahvehane ilk kez 1511 yılında Mekke'de bir caminin yanında, "kahve" içeceğinin tüketilmesi amacıyla ortaya çıkmış ve oradan kuzeye doğru yayılarak İstanbul'a ulaşmıştır. Bu süreç içinde Halep'ten gelen Hakem ve Şam'dan gelen Şems adındaki iki kişi1554 yılında İstanbul'un Tahtakale semtinde ticari bir amaçla ilk kahvehaneyi açmışlardır:

\footnotetext{
"Resmî şekilde açılan ve ticaret siciline kayıt edilerek ticarete başlayan bu kişilerin aldıkları izin, Osmanlı devletinin sosyal bir içecek olarak kahveye ve bu içeceğin hazırlanıp tüketileceği kamusal alan olarak kahvehaneye bakış açısını ortaya koymuştur. Böylece kahve ve kahvehane resmî olarak kabul edilmiş ve o tarihten başlayarak [arada kesintilere uğrasa da] günümüze kadar gelecek bir kurumun ve dolayısıyla bir geleneğin ilk temeli atılmıştır" (Çağlayan, 2012: 102)."
}

Kahvehanenin her yaştan, meslekten, dinden, dilden ve ırktan insanı biraraya getirme potansiyeli zaman içinde bu mekâna bir kimlik kazandırmıştır. Bu anlamda önemli bir buluşma noktası olan kahvehaneler önceleri sadece komşuluk ilişkileri etrafında şekillenen gündelik yaşama, sosyo-kültürel açıdan büyük katkılar sağlamışlardır.

Bu sosyo-kültürel yaşamın gerekliliklerive insan çeşitliliğine göre farklı işlevler üstlenen kahvehanelerin iç mekân dekorasyonları da bu işlevlere hizmet edecek şekilde düzenlenmiştir. Diğer dekoratif öğelerin yanında, çeşitli konular etrafında biçimlenen taşbaskı halk resimlerinin de görsel anlamda bu dekorasyonun bir parçası olduğu bilinmektedir. Ancak içinde bulunduğu mekânın alımlayıcısının görsel ve ideolojik algısına hitap eden tema ve biçimlerde bir yorumlama mekânizmasına göre değerlendirildiklerinde, bu taşbaskıların sadece dekoratif bir öğe olmadıkları açıkça görülmektedir. Bu anlamda kahvehanenin çeşitli işlevleri ile taşbaskı halk resimlerinin tematik olarak biçimlendirilmesi arasında bir ilişki kurmak mümkündür.

Tarihsel gelişimi içinde kahvehanelerin 'kahve' içeceğini tüketme olarak bilinen ilk amacı zamanla ikincil konuma gerilemiş ve kahvehaneler toplumsal gereksinimler olarak değerlendirebileceğimiz başka işlevlere kaynaklık eden araçsal mekânlar haline gelmiştir. Bu işlevlerden ilk akla geleni kahvehanelerin esas olarak sohbet ve eğlence mekânları olmasıdır. Nitekim Hattox'a göre, bu işlevler, mekânın genel atmosferi içinde kendiliğinden ortaya çıkmaktadır: "Konu ciddi ya da 
önemsiz, yüce ya da rezilce amaçlara dönük olsun, herhalde hiçbir yer sohbet havasına kahvehaneden daha uygun düşemezdi. Büyük şehir kahvehanesinin kamçıladığı konuşmalar belki de caminin hasır ve kilimleri üstünde yapılandan daha büyük bir canlılık kazanmaktaydı" (Hattox, 1998:88).

Kahvehane sohbetlerini bu mekânın yaratıııı̆ğını ürünü olan hafif, boş ve sıradan sohbetler olarak değerlendirenler yanında, bu düşünce karşııında yer alanlar da vardı. Buna göre, "kahvehaneler şairler ya da yazarların en son yapıtlarını eleştirel bir izleyici kitlesinin değerlendirmesi için sundukları, bazen müşteriler arasında sanat, bilim ve edebiyat üzerine hararetli tartışmaların yaşandığı bir tür edebiyat forumu gibiydi" (Hattox, 1998: 88-89). Hatta bu yönüyle kahvehaneler, aynı zamanda enformel bir eğitim kurumu rolünü de üstlenmekteydi. Nitekim,

“...kahvehanelerin Birinci Dünya Savaşı'ndan önce, müşterilerin takip edebilmesi için, pek çok süreli yayını masaların üzerinde sergilediği ve bir kısmının tabelalarına 'okuma evi' ya da 'okuma salonu' anlamına gelen 'kıraathane' yazısını astıkları bilinmektedir. Dolayısıyla kıraathanelerde kahvehanelerden farklı olarak yapılan iş 'okumak' olup, Cumhuriyet öncesinde okuma işinin okur-yazar olmayan kitle için bir gönüllü tarafından yapıldığı ve herkesin memleket meseleleri hakkında bilgilenmesinin sağlandığı belirtilmektedir (Şahbaz, 2007:88)."

Eğitsel işlevi dikkate alındığında, kahvehanelerin sadece zaman öldürülen bir yer olmadığı kesindir. Bu mekânlar kişiler arasındaki sohbet sürecinde bilgi alışverişinin mümkün olduğunca eksiksiz olması için sosyal sınıf ve statü farkının ortadan kaldırması ve herkesin birbiriyle iletişime geçmesini sağlaması yönünden de önemlidir. Öte yandan kahvehanelerdeki bu iletişim zamanın iktidar erki için bir potansiyelede dönüşmüştür. Bu anlamda yönetimin lehine bir "haberleşme ve bilgilenme" işlevini de üstlenen kahvehaneler,Hattox'un aşağıdaki ifadelerinde gönderme yaptığı gibi zaman zaman bir tür "istihbarat" mekânı haline gelmişlerdir.

"Gazetelerin ve halk forumlarının yerini alan kahvehaneler kısa sürede Saray ya da Kapı ile ilgili haberlerin kulaktan kulağa yayıldığı birer bilgi alışverişi odağı haline geldi. Mevki sahibi kişilerin de bulunduğu bu tür yerlerde, çok eski ve yaygın bir gelenek olan haber 'sızdırma' yöntemi herhalde bilinmeyen bir 
şey değildi. En son haberleri, daha doğrusu en taze söylentileri duymak isteyen bir kişinin yapması gereken tek şey kısa bir süre kahvehanede oturmaktı (Hattox, 1998:89)."

Halkın kahvehanelere olan yoğun ilgisi ve yönetime karşı hoşnutsuzluğun yüksek sesle, topluca dile getirilerek devlet sohbetinin koyulaştırılması, zaman zaman bu kahvehanelerin güvenlik nedeniyle kapatılmasına neden olsada, geçmişten bugüne yaygın birer kültür mekânı olmayı başarmışlardır. Böyle tarihsel bir süreklilik içinde, kahvehaneler kahve tüketimiyle ilgili ilk andaki işlevinden farklı olarak zaman içinde, sohbet, eğlence ya da dinlenme mekânı olmuş, sözlü kültür unsurlarını devam ettirerek ve güncel olaylar hakkında bilgi vererek enformel bir eğitim kurumu rolünü üstlenmiş, haberleşme ve bilgilendirme işleviyle bir iletişim mekânı ve buna ek olarak, yapılan siyasi tartışmaların aleyhinde kullanıldığı bir istihbarat mekânı olmuştur. Çok işlevli bu yapısı ise, kahvehaneleri, toplumsal aktivitelerin merkezi haline getirmiştir.

Illk ortaya çıktığı andan itibaren hızla sayıları artan kahvehaneler, mahalle, esnaf, yeniçeri, âşık, çalgılı, meddah, esrarkeş vb. gibi mekân, insan ve kültür çeşitliliğine bağlı olarak farklı türlerde ortaya çıkmış ve yaygınlaşmıştır. Bu türler içinde en bilineni "mahalle kahvehaneleri" dir.

Tarihsel bir süreklilik içinde günümüze kadar ulaşmış mahalle kahvehaneleri, tüm kahvehane türleri için belirleyici bir prototip olma özelliğine sahiptir. "Çeşitli sorunlar çerçevesinde örgütlenme bilincinin ilk tohumlarının atılığı bu tür kahvehaneler 'kültürel paylaşmanın dengeli bir biçimde' gelişmesine de zemin hazırlamıştır" (Evren, 1996: 49). Bu sayede en yaygın kültürel mekânlar olmayı başaran mahalle kahvehaneleri toplumsal iletişim merkezleri olarak önem kazanmış ve sosyalleşme açısından gündelik yaşama büyük katkılar sağlamışlardır.

16. yüzyılda mahalle kahvehaneleri ile birlikte ortaya çıkan "esnaf kahvehaneleri" ise daha çok iktisadi yaşamın yoğun olduğu yerlerde yaygınlaşmışlardır. Dolayısıyla müşteri potansiyelini genellikle işsizlerin oluşturduğu bu mekânlar "zaman öldürme ve eğlenmekten çok, iş kolları arasında dayanışma sağlamak, iş bulmaya yardımcı olmak gibi konulardaki yardımlaşmaları amaçlamaktadır. Dolayısıyla esnaf kahveleri bir meslek kahvesi ve lonca teşkilatının bir şubesi gibi görev yapmıştır" (Şahbaz, 2007:55). 
"Yeniçeri kahvehaneleri" ise mahalle ve esnaf kahvelerinden farklı bir kimlik ve disiplin içerisinde ortaya çıkmıştır. Bu kahvehanelerin, “'ocak' kurallarının olması yönüyle askeri, Bektaşîikle özdeşleşmesiyle dinsel, 'devlet sohbeti' denen muhalif düşünce ve öfkelerin dile getirilmesiyle siyasal, açılmasılyla ilgili bazı geleneksel törenlerin yapılmasıyla da folklorik işlevleri olmuştur" (Yıldız, 2007:43).

Yeniçeri kahvehanelerinin bir uzantısı olarak ele alınabilecek "semai kahvehaneleri" ise, "klasik kahve ile tiyatro arasında 'köprü' vazifesi görmüşlerdir" (Yıldız, 2007:44).

Kahvehanelerin 16. yüzyılda Türkiye'de açılmaya başlamasıyla benzer tarihlerde âşık tarzı şiir geleneğinin de kendini hissettirmeye başladığından söz edilmektedir. Buna bağlı olarak ortaya çıkan bir başka kahvehane türü de "âşık kahvehaneleri" dir. Âşıkların toplandıkları ve dini bir kimliği bulunmayan bu mekânlarda sıklıkla tekkenin klasik dini öğretileriyle tatmin olmayan Bektaşi tarikatına bağlı Yeniçeri Ocağı' nın ordu şairlerine de rastlanmaktaydı.

Âşık kahvehaneleri "kentteki taşranın sesi ve sıradan insanın gündelik olaylar karsısındaki duygularını, düşüncelerini yansıtan bir forum' olarak tanımlanmakta ve kent ile kırsal kesim arasında bir çeşit iletişim kanalı görevini üstlenmektedir" (Işın, 2001: 36; Akt, Şahbaz: 2007: 58).

Daha çok iki namaz arasında gidip gelinebilsin diye camilere yakın yerde kurulan ve kıraathanelerle birlikte ilk defa Karagöz, hokkabaz, ortaoyunu vb. millî oyunların sergilendiği yer olması bakımından "imaret kahvehaneleri" (Şahbaz, 2007:66) ile kendine has özellikleriyle ortaya çıkan "sahil kahvehaneleri" de kahvehane türleri arasında son derece önemlidir.

Siyasi görüş ve dini inanç faktörünün etkisiyle, insana ve kültüre göre farklılıklar gösteren ve çoğunun gösterişli olduğu bilinen kahvehaneler dekorasyonları itibariyle de çeşitlilikler göstermektedirler. Örneğin, bir Bektaşi babasının bulunmasından dolayı "Bektaşi tekkesi" olarak anılan yeniçeri kahvehanelerinin iç mekân tasarımlarında "peyke, sofa ve bir saz yerinin yanı sıra kahvehanenin en hâkim yerinde Bektaşi şeyhinin oturması için bulunan "baba sofrası' bulunmaktadır" (Evren, 1996: 56-60). Yeniçeri kahvehanelerinin bir uzantısı olarak görülen 
semai kahvehaneleri ise, "gösteri yapılan sahnemsi bir yükselti ile tümüyle tiyatrovari bir düzen oluşturmasıyla dikkat çekmektedir" (Yıldız, 2007:44). Bahsedilen diğer kahvehaneler de türlerine göre çeşitli dekoratif özellikler göstermektedir. Bundan yarım yüzyıl öncesindeki genel görünümü veiç mekân tasarımına göre kahvehane şöyle tanımlanmaktadır:

"Genel olarak, kahvehane, 'orta meydanı' olarak adlandırılan bir avludan oluşmaktadır. Bu mekânın üç ya da dört tarafı bir metreye yakın oturma yerleriyle çevrelenmiştir. Bir kısmında ise, ayakkabıların çıkarıldığı 'kunduralık' bulunmaktadır. Oturulan mekân, yerden 20-30 cm. yüksektir. Orta yerde şadırvan ya da benzeri bir havuz bulunmaktadır. Kahve ocağının hemen karşısında, 20-25 kişinin sığabileceği büyüklükte 'kerevetli baş sedir' bulunmaktadır. Buraya daha çok nüfuslu kimseler otururlar. Tiryakiler ise, baş sedirin yanında, önünde post bulunan yerde oturmaktadırlar. Kahvenin en hakim yerinde ocak bulunmaktadır. Burada çeşitli raflar bulunur. Bu raflarda, kahve malzemesi, çubuklar, bazısında nargileler, diş çekilen kahvehanelerde ise diş çekim malzemeleri bulunur. Kimisinde ise, tıraş malzemeleri bulunur (Yıldız, 2007:47)."

Kahvehane kültürünün bütün bu kendine has özelliklerini yansıtan dekoratif öğeleri içinde dikkat çeken bir başka öğe ise; 'taşbaskı halk resimleri'dir. Müslümanlardaki 'suret yasağı' anlayışının kırılma noktalarını oluşturan bu resimler, düşünsel anlamda birer başkaldırı merkezine dönüşen kahvehanelerin, sanat nesnelerini oluşturmakta ve çok zengin bir konu çeşitliliğiyle karşımıza çıkmaktadır. Bu anlamda Özcan sivil vatandaşların ve devlet memurlarının devam ettiği kahvehaneleri, "zamanın ekonomik, siyasî, sosyal konularının konuşulduğu, aynı zamanda bu ve başka konuların baskı resimlerle de sergilendiği birer galeri"ye benzetmekte ve eklemektedir:

“Osmanlı ve Cumhuriyet dönemlerinin sosyal olaylarını, geçmişin hikayelerini, gerçek, gerçek üstü birçok konuda resimleri bir arada görmek, seyretmek mümkündü. Konulardan birkaçını sayacak olursak; donanma, kale, top, cami, kahramanlık sahneleri, eski *efsaneler, gerçek üstü olaylar, varlıklar, ulusal kahramanlar, kerametler, manzaralar, Türk büyüklerinin portreleri, sembolik anlatımlar, aşıkların hikâyeleri, dinî konular, savaşlar, tılsımlar, hüsn-i hat ile çeşitli konularda resimler 
(Özcan,http://www.ges.gov.tr/makale_detay.php?newsld=12\& page $=$ all\&language $=$ tur $\&$ next $=1) . "$

Halk sanatlarının önemli ve yarım yüzyıl öncesine kadar da yaygın bir dalını oluşturan bu resimler, içine doğdukları kültür içinde kuşkusuz dekorasyon olmaktan öte bir amaca hizmet etmişlerdir. İdeolojiyle ve dünya görüşüyle uyumlu olarak, anlaşılabilir, sade duygu ve düşüncelere en yakın biçimlerle aktarılan bu resimler, mekâna göre türlü gerekçelerle biçimlendirilmişlerdir. Bir başka ifadeyle, çok zengin bir konu çeşitliliğine sahip bu resimlerin çeşitli fonksiyonları, kahvehanelere asılmalarında belli başlı amaç ve işlevleri bulunmaktadır.

Sözlü gelenekten derlendikleri düşünüldüğünde, kuşkusuz 'görsel'in 'sözel dil'i desteklemesi bu amaçlardan ilk ve en genel olanını oluşturmaktadır. Örneğin imaret kahvehanelerinde ya da kıraathalerde "Karagöz göstermelikleri" de denilen ve "çiçekli saksılar, fıskiyeli havuzlu bahçeler, köşkler, süpürgeye, yahut küpe binmiş cadılar, yedi başlı ejderler, anka kuşları, sıra dağlar" (Aksel,2010:80) gibi oyuna başlamadan hemen önce konuyla ilgili ya da ilgisiz perdeye çıkarılan birtakım görseller böyle bir ilişki ağını ortaya çıkarmaktadır. Öte yandan görsel ile sözlü geleneğin birbirlerini beslediği böyle bir disiplinlerarasılığa "hikayeye iri ve basit elemanlarla yardımcı olmak" (Derman, 1988:16) amacıyla yapılmış İran göstermeliklerinde de rastlanmaktadır.

Dönmezer, "Taşbaskıda Halk Sanatı ve Akademik Sanat adlı tezinde bu ilişkiyi doğrularken, İran kahvehanelerinde bugünde devam eden 'Şehname' anlatılarında, aynı göstermeliklerin çağın iletişim aracı olarak kabul edilen televizyona bile taşındığını ve hikayeye hizmet etmek amacını sürdürdüğünü belirtmektedir" (1993:29). İşte tam bu noktada, kahvehanelere asılan taşbaskı halk resimlerinin kültürel varlığın sürdürülmesinde önemli bir rolü üstlendiği de göz ardı edilmemelidir. "Dilden dile aktarılırken, kalıcılık payı azalan ve doğruluk derecesi anlatıldıkları zamanın ve kişilerin katkı paylarıyla değişen sözlü kültür ürünleri ancak basılı olmaları halinde gelecek kuşaklara aktarılabilir" (Dönmezer, 1993:16). Bu anlamda bir dönemin zevk ve kültürünü yansıtan bu resimlerin, tarihsel bir süreklilik içinde günümüze kadar gelen kahvehanelere asılması, kültürün gelecek kuşaklara aktarıması adına entelektüel bir çaba olarak da görülebilir. Nitekim, kahvehanelerin yaygınlık kazandığı dönemde bu mekânı mesken tutmuş halk içinde okur-yazar oranının son derece düşük olduğu da bilinmektedir. Bir 
bakıma bu dönemde taşbaskı resimlerin okuma-yazma bilmeyenler için bir yazı işlevi görmesi amacıyla kahvehanelere asılmış olması muhtemeldir.

Elbette sözel dili destekleyerek kültür aktarımı yapmak bu taşbaskıların kahvehanelere asılmasının tek nedeni değildir. Taşbaskı halk resimleri halkın hayal gücünde egemenlik kuran, çok etkili, temsil ettiği düşüncenin yerini tutan bir sembol niteliği taşımakta olup, özellikle tarikatlara özgü sembollerle oluşturulan resimler mekânla tam bir uyumluluk göstermektedir. Dolayısıyla dönemin otorite karşıtı tarikatlarının resmin sembolik dilini kendileri için bir kamuoyu oluşturmak ve bu kamuoyunun belleğini canlı tutabilmek için kullanmış olmaları hiçte uzak bir intimal değildir. Öte yandan daha öncede belirtildiği gibi kahvehanelerin tekke, zaviye ve cami vb. gibi ibadet mekânları karşısında İslam'ın heterodoks yorumunu benimseyenler için alternatif bir ibadet mekânı olarak görülmesi de, resimlerin dinsel bir ikon gibi görülüp kahvehanelere asıldığı düşüncesini de akla getirmektedir. Dolayısıyla bir tür kavram birliği duygusu yaratılarak mekânla tam bir uyumluluk içinde görselleştirilmiş bu resimler, Alevi, Bektaşi, Mevlevi vb. tarikatlar için sembolik değeri olan resimler olup, sıklıkla aşık, semavi ve yeniçeri kahvehaneleri gibi tarikat etkisi altındaki kahvehanelerde görülmektedir.

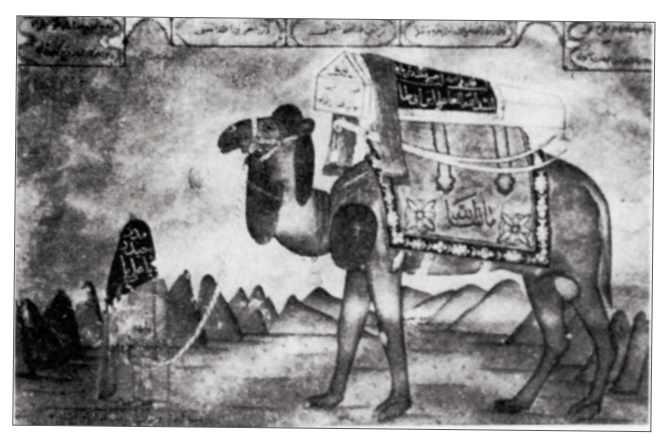

Resim 1:Hz. Ali'nin Devesi, (Ankara Etnografya Müzesi.)

Hacı Bektaşi Veli, Karacaoğlan, Âşık Garip, Âşık Ömer ve Mevlana ile, Hz. Ali'nin Devesi, Zülfikar resimleri gibi Hazreti Ali ve maiyetine ait resimler konu ve motif bakımından böyle bir tarikat etkisi altında oluşturulmuş resimlerden birkaçıdır. 
Erinç, 'Resmin Eleştirisi Üzerine' adlı denemesinde "tipik bir bildiriyi oluşturan 'bu ne anlama gelebilir' denebilen en çağdaş -en şekilsizresmin bile en azından o resim için 'ben de varım' niteliğinde çözümlenebilecek bir iletisi olduğunu söylemektedir" (Erinç, 2004: 53). Buna göre, ilkin bir iletiyi açığa vurmalarıyla sembolik değer taşıdıkları tarikat için bir temsil aracına dönüşen resimler, asıldıkları kahvehanelerde, gören göz üzerinde tahakküm kurmakta ve temsil ettikleri kişi ya da grupların maddi ve manevi varlığının onaylanmasına hizmet eden bir tür görsel manifestoya dönüştürülmektelerdir. Böylece dönemin ideolojisi ve kimlik talepleri arasında, mücadele düzeyinde kurulmuş birer imgeye dönüşen resimler, 'varolma' duygusuyla beraber sanatın 'din' ile kurduğu sembolik bir bağ ile aynı zamanda temel insani bir güdü olan 'bir gruba ya da sınıfa aidiyet duygusunu da temin etmektedirler.

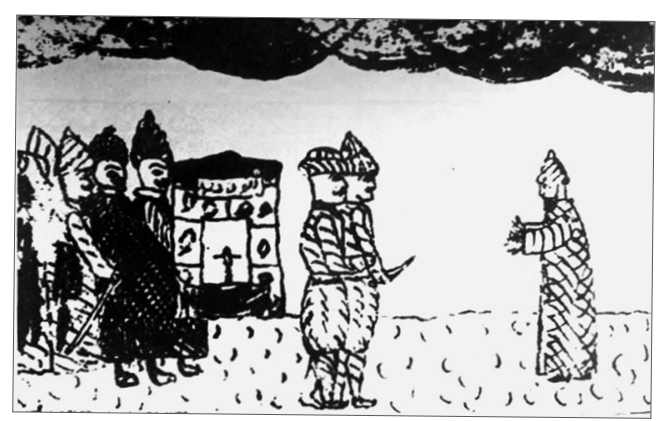

Resim 2: Tıflî Efendi Aksaray'dan giderken arkasından Yeniçeri Ağası'nın geldiğini gösteren bir taşbaskı. (Gül Derman'ın Resimli Taş Baskısı Halk Hikayeleri" adlı kitabından temin edilmiştir).

Öte yandan tarikat resimlerinin kahvehanelere asılma amacı sadece temsil ya da bir kamuoyu oluşturarak geniş halk kitlelerine seslenilmesi ya da varlığın meşrulaştırılmasıyla sınırlı da değildir. Bu dinsel içerikli resimler, aynı zamanda resimler tarafından temsil edilen şahsiyete ve mensup olunan tarikata da duyulan saygının bir ifadesi olarak kahvehanelere asılmakta, böylece kişinin ya da temsil edilen grubun yüceltileceğine inanılmaktadır. 


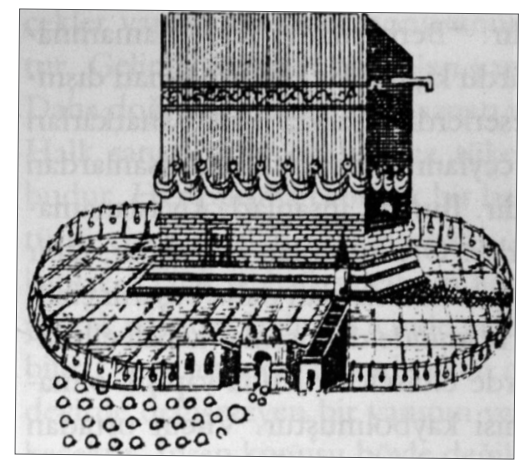

Resim 3:Muhammediye'den; Resul'ü Ekrem'in mağaradan çııı Kâbe'ye gelmesi (Büyük beyaz halka peygamberimizdir).

Yine kahvehanelerde sıkça rastlanılan dini nitelikli 'Kâbe resimleri' de benzer bir anlayışla, "Kâbe'ye duyulan saygının bir ifadesi olarak duvarlara asılmakta ve bunun yanı sıra ibadeti hatırlatma maksadı da taşımaktadır" (Çiçekdal, 2008:239).

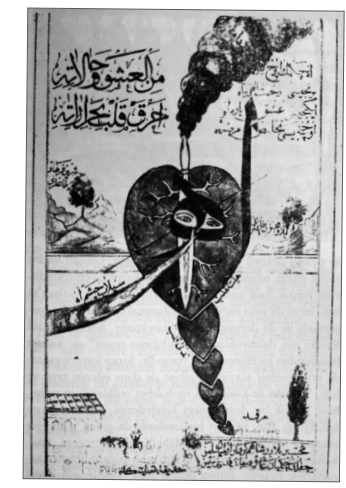

Resim 4:Ah minel-aşk, Abdürreşit, İstanbul Belediye Kütüphanesi.

"Aşkın güzelliğinden çok korkunçluğunun sindiği" (Aksel, 2010:52) 'Ah minel aşk' kompozisyonları ise, ümitsiz aşk hikayelerinin halk gözünde kazandığı biçimi göstermesi bakımından son derece ilgi çekici olup, bunların kahvehaneleri süslemesindeki amacın Allah'a yönelik bir sevginin ifadesi olması muhtemeldir. Bu anlamda halkın içsel dinamizmini canlı tutan bu resimler tarikat ve Kâbe resimlerinde olduğu gibi manevi ve dinsel bir amaca hizmet etmektedirler. Öte yandan yukarıda kahvehanelere asılma nedenleri örneklerle belirtilen tüm dini 
nitelikli resimlerin, asıldıkları mekânlara 'bolluk ve bereket ile sağlık getireceği de yaygın bir görüş olarak belirtilmektedir.

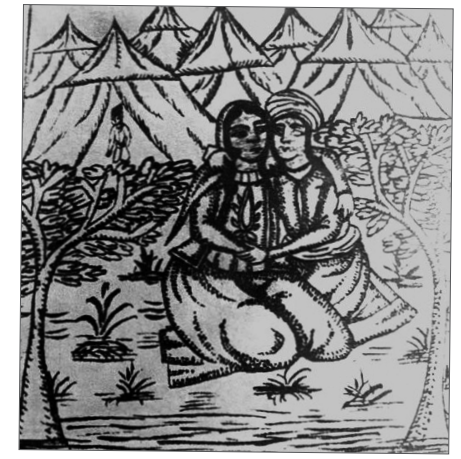

Resim 5: Leyla ile Mecnun (Gül Derman'ın Resimli Taş Baskısı Halk Hikayeleri" adlı kitabından temin edilmiştir).

Mitolojik içerikli bazı resimlerin ise, doğrudan böyle bir amaca hizmet ettikleri bilinmektedir. Örneğin, yarı insan, yarı yılan görünümlü Şahmeran resimlerinin böyle bir tılsımı olduğu düşünülmekteydi. Bu anlamda Anadolu'da asıldıkları yerlerde bir nevi "nazarlık" (Çiçekdal, 2008:37) işlevi gören bu resimlerde, çoğunlukla insanları kötülüklerden koruyan bir güç olduğuna inanılmaktaydı.

Azerbaycanlı Şii Türklerin açtığı Acem kahvehanelerinde ise, “Şehnameden Sührab'ın yedi başlı ejderle boğuşması, Zaloğlu Rüstem'in Dev Sefit'i yenmesi, Behram'ın ejderhayı kovalaması, Rüstem'in Rahs'ı ismi verilen atı; bunlar dısında Behram, Süleyman Peygamber ile Zaloğlu, Hamza Pehlivan'ın Kaf dağını devirmesi, Rüstem ile Sührab gibi hayali korkunç yaratıklarla yapılan mücadeleleri" (Aksel, 2010: 68-70)konu alan taşbaskı resimlerine sıkça rastlanmaktaydı. Bu taşbaskıların konuları itibariyle, performans ve güç göstergelerine dönüştürülmesi kuşkusuz bu mekânların sıklıkla o semtin kabadayılarının ve yiğitlerinin uğrak mekânı olmasıyla ilgiliydi. Bir başka deyişle, yaşamsal olarak asıldıkları kahvehanelerde bakma eyleminin kesintisizliğini, sürekliliğini, zaman ve mekânla dolaysız ilişkisini sağlayan bu resimler, aynı zamanda insanın, nesneler, olgular ya da ilişkiler aracılığı ile kendine baktığı bir ayna işlevi görmekteydi. 


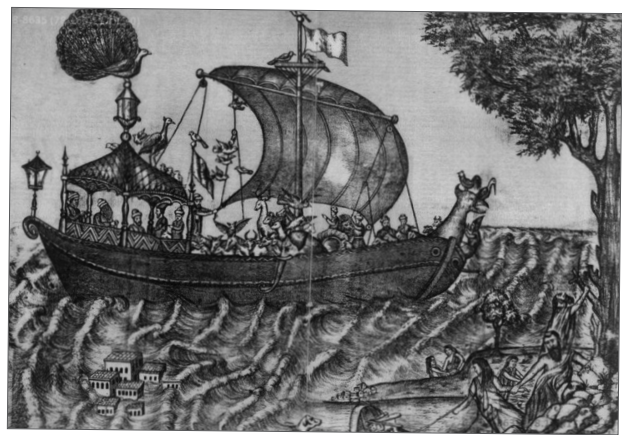

Resim 6: Mehmet Hulusi, Nuh'un Gemisi.

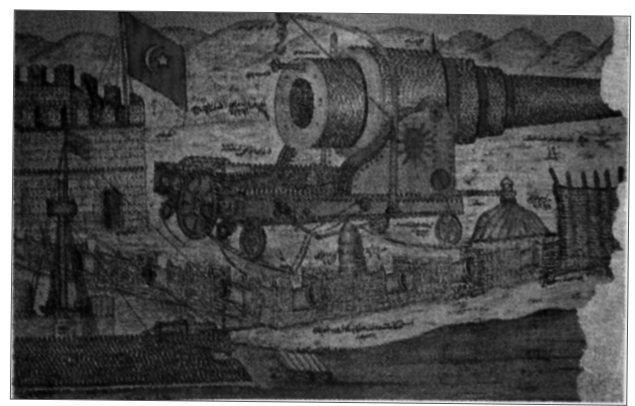

Resim 7:Çanakkale Boğazı. Topun tam altında

“istihkam-ı Devlet-i Osmanniye'den kal'a topu resmi" yazılıdır)

Sahil kahveleri ise;

“ ...kendine mahsus resimlerle dolu olduğu gibi bunların başında denizle ilgili resimler gelirdi. Çoğu İstanbul' da Unkapanında, Samatya'da, Kumkapı'da sahil boyunda, [...] olan bu sıra kahvelerde hayali gemiler, Nuh Tufanı, üç ambarlı Mahmudiye, ...Sultaniye Vapurları, Osmanlı Zırhlı Fırkateyn'i Çanakkale Boğazı, Rumeli Hisarı, hattâ $<<1889$ Paris Şehir Sergisinde demirden imal edilen kulenin resmidir $>>$ yazılı Eyfel Kulesi de bunlar arasında görünürdü. İstanbul'un hususiyetlerini, semtlerini, hattâ satıcılarını belirten resimler de yine duvarlarda göze çarpardı. Ciğerci, Simitçi, seyyar manav gibi... Unkapanı'nda Kandiye'li Emin Babanın gemi resimleri yine o semtte sık sık görüldüğü gibi bazı resimlerin altlarında Ziya, Arif, Hulûsi imzaları bulunurdu. Daha sonraları da Donanma Cemiyetinin bastırdığı Berkisatvet, Muavenet-i Milliye, Sultan Osman zırhlısı resimleri de bunlar arasına katılmışı (Aksel, 2010: 67-68)." 
Çoğunlukla deniz ve denizcilik pratiğiyle ilgili konu ve motiflerin görselleştirildiği bu tür resimler ise, "büyük olasılıkla kahvehanelere Osmanlı donanmasının gücünü belirtmek için asılmaktaydı" (Çiçekdal, 2008:196).

Bunların dışında bir de kahvehanelere devlet büyüklerinin ya da padişahların resimlerinin asılması geleneği vardı. 'Fatih Sultan Mehmet' ve 'Yavuz Sultan Selim' kahvehanelerde resimleri yaygın olarak yer alan padişahlardı. Meşrutiyetten sonra ise, kahvehanelerde ilk defa resmi görülen devlet adamı 'Sultan Reşat'tı" (Aksel, 2010: 67). Malik Aksel'in bizlere aktardığı bilgilere göre bu resimler ise, "eski zamanlarda dönemin siyasi gücünü belirtmek ya da devletin gücünü simgelemek amacılla yapılıp kahvehanelere asılmaktaydı" (Çiçekdal, 2008:269).

\section{Sonuç}

Bütün bu değerlendirmeler gösterir ki, mekân ve insan ilişkisine göre belli başı türlerini sıraladığımız kahvehanelerin bu çeşitliği ve zenginliği yansıttığı taş baskı halk resimleri duvarları süslerken, esasında yukarıda belirttiğimiz pek çok temel amaca hizmet etmektedir. Öte yandan yerleşik bir kanon karşısında insanların pratik davranışlarını yönlendiren bu resimlerin tarihsel bir süreklilik içinde toplumsal düzeni yeniden ürettikleri, başkaldırı ve isyan duygusunun topluma hakim olduğu anlarda ise, toplumsal düzeni dönüştürdükleri ve ona meydan okudukları da gözlerden kaçmamaktadır. Dolayısıyla farklı sosyal ve kültürel grupların belirli zaman ve yerlerde kimliklerini ortaya koymak ve kabul ettirmek için araçsallaştırdıkları bu resimler, üzerlerinde geçmişten bugüne bir takım kültürel kodlar taşımakta ve gelecek kuşaklara kültürel varlığın aktarımasında önemli bir konumda durmaktadırlar.

Günümüzde halk resimlerinin bu zengin içeriğinin ve imgelem gücünün farkında olan ve geleneksel değerlerin yaşatılması ve gelecek kuşaklara aktarılması konusunda duyarlılık gösteren çok fazla sanatçı ve teorisyenin olmadığı görülmektedir. Bu anlamda halk sanatlarına ve halk yaşamına olan ilgisini açıkça yansıttığı teorik çalışmaları ve sanatsal çalışmaları ile Hüsamettin Koçan bu alanda önemli bir yer tutmaktadır.Ayrıca Koçan'ıngeleneksel değerleri, halk kültürünü ve sosyal çevresini belgeleyen taşbaskılar, camaltı resimler, boyamalar ve işlemelerden oluşan geniş koleksiyonu da günümüzde kültür ve sanat yaşamına büyük katkıda bulunmaktadır. Hem bu katkıları, hem de değişim ve dönüşüme olan duyarlıııları ile bu resimler kuşkusuz daha büyük bir ilgiyi haketmektelerdir. 


\section{Kaynakça}

Aksel, Malik, Anadolu Halk Resimleri, Kapı Yayınları, İstanbul, 2010.

Çağlayan, Savaş, "Anadolu'nun İlk Kamusal Mekânı: Kahvehane", Muğla Sıtkı Koçman Üniversitesi Sosyal Bilimler Enstitüsü Dergisi, sayı 29, Güz 2012:102.

Çiçekdal, Yüksel, "Geleneksel Türk Halk Resim Sanatı Camaltı Resimlerinden Örnekler", Yüksek Lisans Tezi, Ankara, 2008.

Derman, Gül, "Resimli Taş Baskısı Halk Hikayeleri”, Atatürk Kültür Merkezi Yayını, Ankara,1988.

Dönmezer, Saime H., "Taşbaskıda Halk Sanatı ve Akademik Sanat", Yayımlanmamış Yüksek Lisans Tezi, Eskişehir, 1993.

Erinç, Sıtkı M., Resmin Eleştirisi Üzerine, Ütopya Yayınları, Ankara, 2004

Evren B.,Eski İstanbul'da Kahvehaneler, Milliyet Yayınları, İstanbul, 1996.

Hattox, Ralph S., Kahve ve Kahvehane, Tarih Vakfı Yurt Yayınları, ìstanbul, 1998.

Işın, E., "Bir İçecekten Daha Fazla: Kahve ve Kahvehanelerin Toplumsal Tarihi", Tanede Saklı Keyif", Yapı Kredi Yayınları, İstanbul, 2001.

Özcan, Yılmaz, "Türk Halk Plastik Sanatı Olarak Taşbaskı (Litografi)KahvehaneResimleri",(erişim)http://www.ges.gov.tr/makale_ detay.php?newsld=12\&page $=$ all\&lana $e=$ tur\&next=1, 23 Nisan 2011 .

Şahbaz, Selin, "Geçmişten Günümüze Kahvehaneler, KahvehanelerinSosyal Yaşamdaki Yeri ve Önemi: Aydın Merkez Örneği", Yüksek LisansTezi, Aydın, 2007.

Yıldız, M. Cengiz, Kahvehane Kültürü, Beyan Yayınları, İstanbul, 2007. 